\title{
Reaching out to our youth
}

\author{
Jessica-Sheay Verrall ${ }^{1}$ and Soebur Razzaque \\ Centre for Astro-Particle Physics (CAPP) and Department of Physics, \\ University of Johannesburg, Auckland Park 2006 \\ South Africa \\ E-mail: jessica-sheayv@uj.ac.za
}

\begin{abstract}
One of the main goals of the outreach activities by the Centre for Astro-Particle Physics (CAPP) at the University of Johannesburg (UJ) is to understand to what extent South African high school students are aware of astronomy/astrophysics. CAPP will share what they have done so far in order to reach out to high school students. Adopting strategies from research or suggestions from experienced persons will be used to motivate students into astrophysics and science in general. In today's society one of the best platforms to get information to our youth is social media. It is one of the main platforms of interaction for millennials and generation $Z$. The social media platforms being used by CAPP will also be mentioned. Ideally students one day will be able to see a future for themselves in astrophysics.
\end{abstract}

\section{${ }^{1}$ Speaker}




\section{Introduction}

The Centre for Astro-Particle Physics (CAPP) is the new research Centre at the University of Johannesburg (UJ) and the Centre began in July 2018. As the name suggests the Centre is focused on cross-disciplinary research with topics from Astrophysics and Particle Physics. For the year 2019, one of the goals of CAPP was to reach out to South Africa's youth in order to create awareness to students about the possibilities of pursuing science as a future career.

We also wanted to have an idea of how much high school students knew about astronomy. Our first step was to identify the generations we were going to deal with. Those generations being Generation $\mathrm{Z}$ and Millennials. Since social media is an effective tool to communicate with high school pupils, we are making use of this platform to communicate with our younger generations.

\subsection{Activities performed by CAPP}

\subsubsection{Publishing of CAPP's newsletter}

We designed newsletters which contained information about the Centre and our activities such as the research taking place by our students and post docs, the latest astronomy and astrophysics news and discoveries, bursary opportunities, our pages on social media platforms, and our most recent edition had an astrophysics themed crossword puzzle for our viewers to play. With our social media platforms and outreach activities, we advertised our website and newsletters in the hopes that they can reach a wide range of students.

\subsubsection{Brochure to advertise the centre}

We designed a brochure for distributions at student events. The brochure contained information for readers about the Centre and the opportunities it presents. We also mentioned in the brochure some information about some of our collaborations.

\subsubsection{Social Media and what is the take of Millennials and Gen $\mathrm{Z}$ on science}

In order to reach out to our youth, CAPP created an Instagram, Facebook and LinkedIn profile. The handles for each account were @ujcapp, Centre for Astro-Particle Physics, and UJ CAPP (Centre for Astro-Particle Physics) respectively.

These social media platforms allowed for us to share the latest news and information about the Centre with mainly our youth as well as all other age groups. At the time of the HEASA Conference the CAPP social media accounts were still very new, having a total of 77 followers. At the time, each post made by the centre on our Instagram account would get between 5 and 25 likes, with some comments. It shows that some posts appeal to our followers more than other posts. The majority of the liked posts being focused on public lectures, group photos, and the engagement activities of the members of CAPP, more so than just scientific posts. A lot of the Instagram followers on our account are of the high school going age due to our visit at Marais Viljoen. We have had numerous requests on our LinkedIn account, all from people of different ages and backgrounds, which has left CAPP feeling positive.

These generations are curious about science and ultimately want their jobs to be their passions. They are intricately and consistently connected to social media which, therefore, makes technology both an inspiration and medium for innovation for them (Ossola, 2019). 


\subsubsection{Presentation at Marais Viljoen High School}

On the $3^{\text {rd }}$ of August 2019, myself and Professor Soebur Razzaque went to Marais Viljoen High School in Johannesburg in order to give a presentation to the grade 11 and 12 students. Our presentation consisted of information about CAPP, information about astronomy in South Africa and we also included a quiz at the end of the presentation.

We gave our presentation using the Mentimeter (Warström 2014). Mentimeter enables users to share knowledge and real-time feedback on their mobile or other devices with presentations, polls or brainstorming sessions in classes, meetings, gatherings, conferences and in other group activities.

We began by asking the students some general knowledge questions about astronomy and, as mentioned above, they answered on their phones and all their results were presented to them in real time.

We then proceeded to tell students about the Centre and what we have to offer them regarding bursaries. We also told them what they need in high school (in terms of subject choices and marks) in order to study astrophysics at University level.

After we were done presenting, we quizzed them based on the information we presented to them, to see if they were paying attention. Again, majority of the students got the answers correct. We then gave a prize to the top three learners who got the most answers right in the quiz (see Figure 1 and 2).

As part of the presentation, we asked them what they had in mind for themselves as a possible career choice in the future, some students weren't sure, others gave us nice answers of what they would like to do and the rest didn't take the questioning very seriously (see Figure 3).

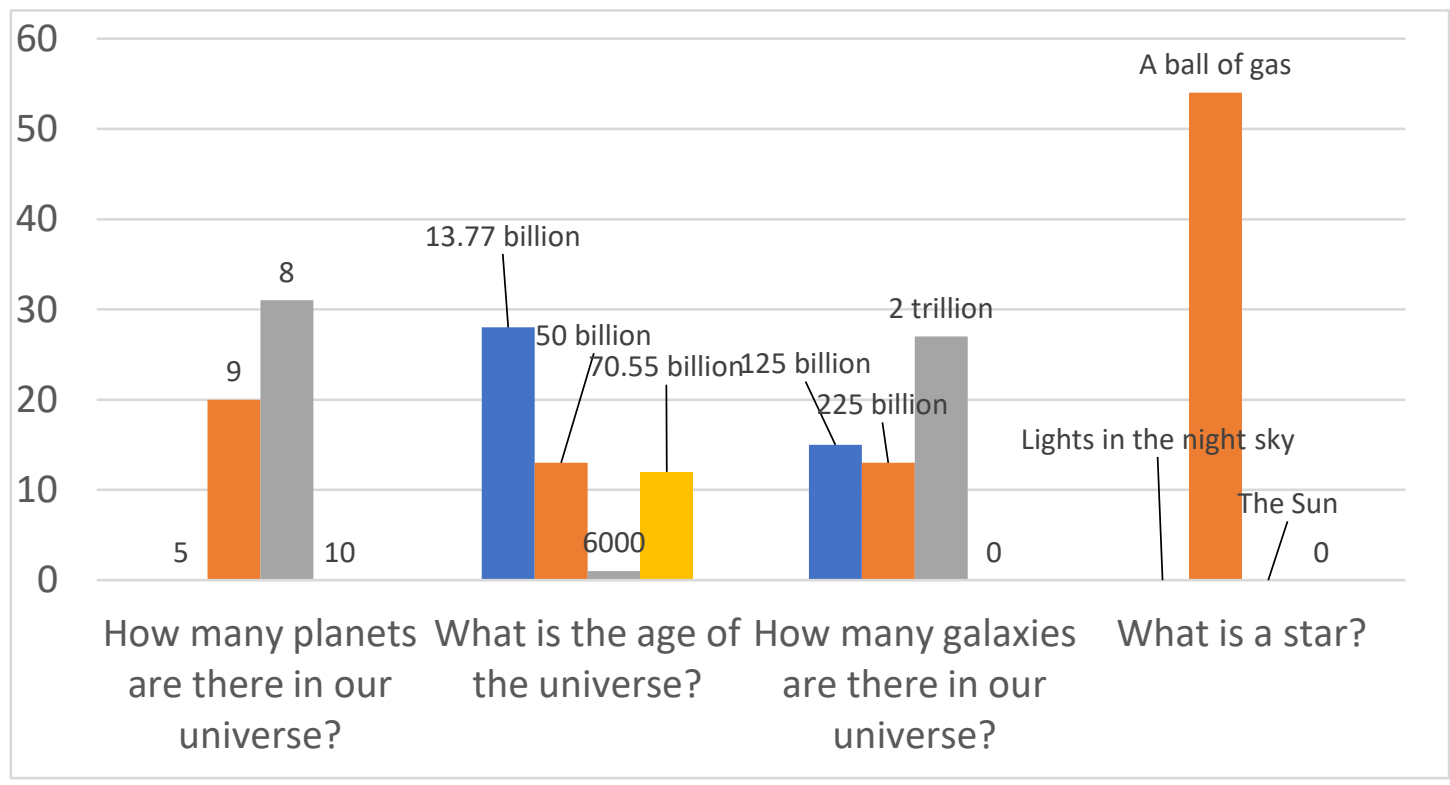

Figure1: A Bar graph of the questions asked during the Marais Viljoen High School presentation and the various answers which the students selected. As can be seen, majority of the students got the answers correct. 


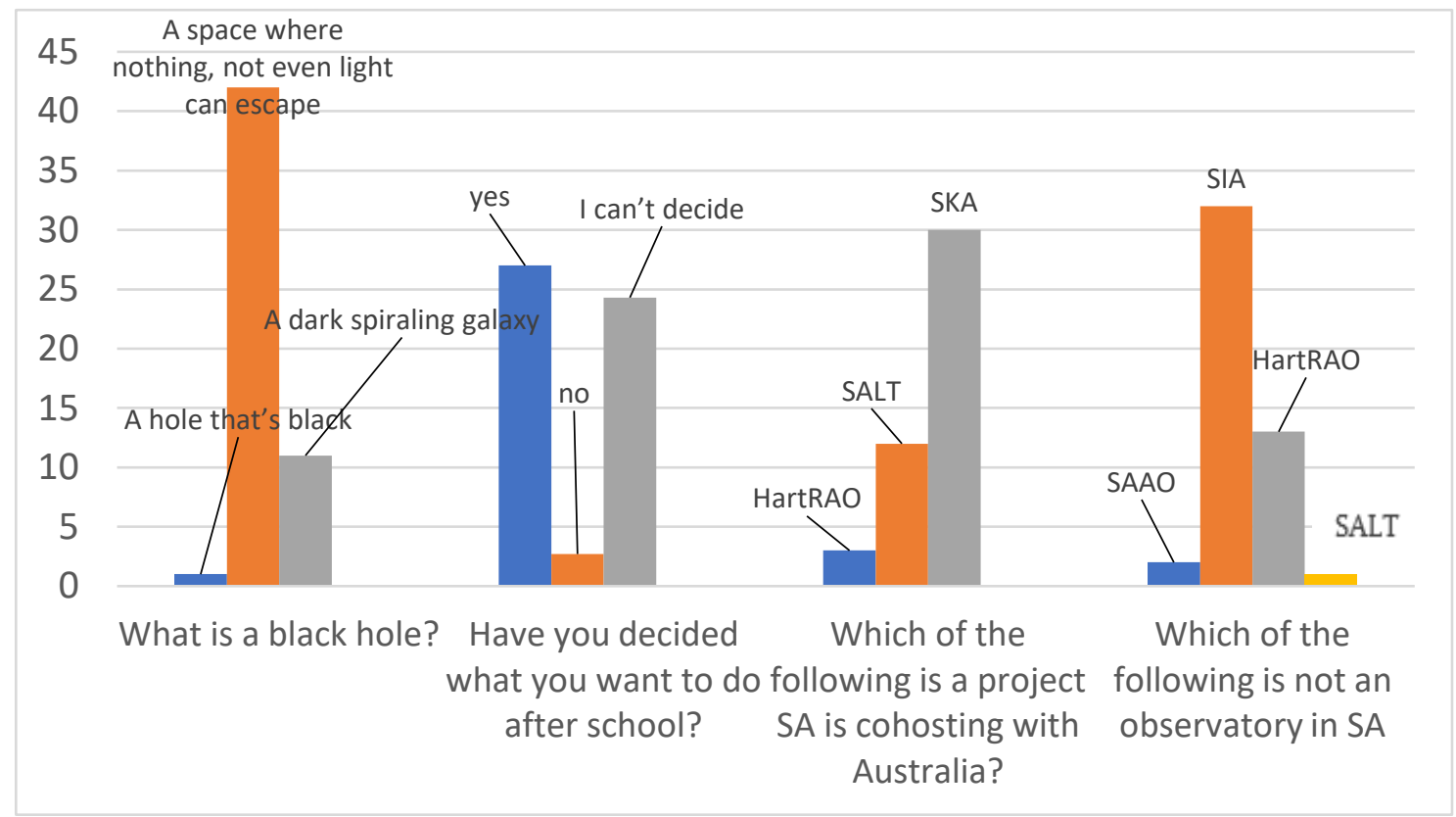

Figure 2: A Bar graph of the questions asked during the Marais Viljoen High School presentation and the various answers which the students selected. As can be seen, majority of the students got the answers correct.

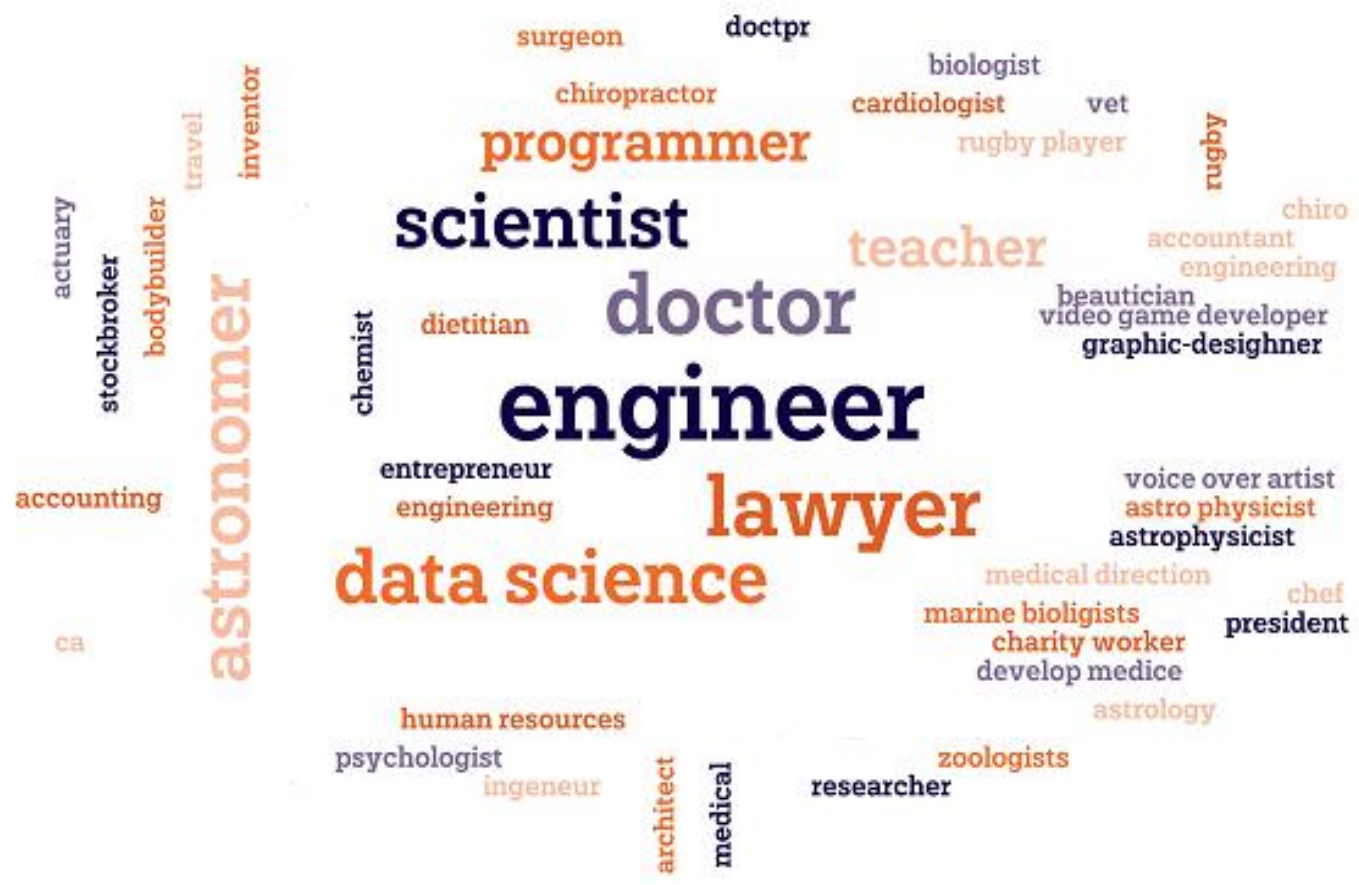

Figure 3: A word cloud of some of the possible careers the High school students had in mind for themselves in the future. 
The activities were found to be very engaging and useful in obtaining knowledge from students. The more activities CAPP can perform the more data we will be able to use in further research to help with outreach activities. In future CAPP would like to take the above points and use them to create a broader range of outreach for the youth in the area as well and possibly, in the future, the country.

\section{HEASA Conference presentation}

At the HEASA Conference 2019, I presented these statistics. At the end of my presentation, I asked the audience if they had any suggestions for better ways of reaching out to our youth and we were given the following suggestions;

- Provide a training course for high school teachers. This will help educate them with information outside of what they learnt in their course studies to become a teacher. This will provide teachers with relevant information about astronomy and astrophysics in order for them to give their students necessary and correct information.

- Create a "mini conference" for all high school students where they can discuss the latest news in astronomy and astrophysics. This information can come from any platform that they obtained the information from. Such as social media, newsletters, magazines, internet searches, etc.

- Form a "collaboration" with the University of Namibia in order to increase the audience receiving our newsletters as well as collectively encourage UNAM students/ staff with outreach activities such as presenting at schools.

- Get in contact with other universities in South Africa and make an effort to collaborate with them and their outreach activities.

- Have a camp/getaway for high school students. Plan a camp for some high school students who are interested in astronomy. This camp should include some fun games which teach the students about physics, it should contain some presentations, some goodie bags and group activities where students need to work together in order to accomplish a task / experiment/ research activity (obviously astronomy related). This should be a sponsored event and should take place over the course of at least a week.

For additional resources, see the following article Pompea and Russo (2020).

All of these suggestions we found to be very helpful and in the new year CAPP would like to implement some of these suggestions.

The benefit we have as influencers, is that most of these people we are trying to reach out to are still young and early in their careers with some form of interest in science, we therefore now have the opportunity to take this interest and hopefully progress it into their passion.

\section{Conclusion}

Through the activities of CAPP we were able to gauge an estimate of the level of knowledge that the high school students had for astronomy within Marais Viljoen. Based on the data we obtained we could see that majority of the students had a good background in astronomy, however, visiting one school is not a large enough sample in order to fully understand the awareness of all pupils within the local area. We are also not sure if the knowledge they possess was learnt at school, the news, or social media etc. The results would be far more beneficial if more schools are to be visited in future and if a more accurate survey, of where they learnt about astronomy, were conducted. 


\section{References}

Ossola, A. (2019). Why Millennials \&\%\#@! Love Science. [online] The Atlantic. Available at: https://www.theatlantic.com/education/archive/2014/10/why-millienials-love-science/382015/ [Accessed 2019].

Pompea, S.M. and Russo, P. (2020), Annual Reviews of Astronomy and Astrophysics, 58, 313.

Warström, J. (2014). Mentimeter, https://www.mentimeter.com, Stockholm, Sweden. 